\title{
Penguatan Karakter Peduli Lingkungan melalui Program Cinta Lingkungan di MIM Kranggan, Sukoharjo
}

\author{
Yakub Nasucha ${ }^{1}$, Laili Etika Rahmawati ${ }^{2}$, Yasinta Silviana ${ }^{3}$, Ruis Udin ${ }^{4}$, Siti Atitah ${ }^{5}$, Widi Astuti ${ }^{6}$, \\ Niko Indriyani ${ }^{7}$, Isnaini Safitri ${ }^{8}$, Fera Diah Ayu K. ${ }^{9}$, Sulistyo Aji ${ }^{10}$, Evatias Nirmala ${ }^{11}$, Sri Arfiah ${ }^{12}$ \\ 1,2,3,4,5,6,7,8,9,10,11,12 Fakultas Keguruan dan Ilmu Pendidikan, Universitas Muhammadiyah Surakarta, \\ Indonesia
}

\section{INFORMASI ARTIKEL}

\section{Histori Artikel:}

Submit: 12 Agustus 2020

Revisi: 30 Agustus 2020

Diterima: 1 September 2020

Publikasi: 3 September 2020

Periode Terbit: Desember 2020

\section{Kata Kunci: \\ karakter. \\ peduli lingkungan. \\ sekolah dasar}

\section{Correspondent Author:}

Yakub Nasucha

Fakultas Keguruan dan Ilmu Pendidikan

Universitas Muhammadiyah Surakarta,

Indonesia

Email: yakub.nasucha@ums.ac.id

\begin{abstract}
ABSTRAK
Indeks Perilaku Peduli Lingkungan (IPPL) masyarakat Indonesia pada tahun 2012 berada pada kisaran angka 0,57 dari angka mutlak 1 (Kambuaya, 2013). Berdasarkan data tersebut, menunjukkan kepedulian lingkungan masyarakat Indonesia masih cukup rendah. Hal ini sejalan dengan kondisi yang ditemui tim KKNDik FKIP UMS MIM Kranggan. Oleh karena itu, tim KKNDik FKIP UMS MIM Kranggan mencanangkan dan melaksanakan program cinta lingkungan untuk menguatkan karakter peduli lingkungan siswa di MIM Kranggan. Program cinta lingkungan ini merupakan integrasi dari beberapa kegiatan, sehingga metode yang digunakan pun beragam, yaitu sosialisasi, pemberian reward, gerakan kebaikan, dan praktik langsung. Program cinta lingkuan ini terdiri dari empat kegiatan, yaitu sosialisasi PHBS (Perilaku Hidup Bersih dan Sehat), lomba kebersihan kelas, gerakan membawa tumbler, dan gerakan menanam pohon. Program ini menghasilkan hasil yang positif, yaitu berupa meningkatnya kepedulian siswa untuk menjaga kebersihan lingkungan sekolah. Pengabdian ini jika dilakukan di seluruh Indonesia, mampu menciptakan manusia-manusia yang bertanggung jawab dan memberikan dampak yang siginfikan terhadap terjaganya lingkungan di Indonesia, serta mampu memberikan efek positif pada sektor yang lain, seperti terjaminnya kesehatan masyarakat Indonesia.
\end{abstract}

\section{Pendahuluan}

Kepedulian terhadap lingkungan pada masyarakat Indonesia masih terbilang rendah. Hal ini sesuai dengan pernyataan Kementerian Lingkungan Hidup, bahwa masyarakat Indonesia sebagian besar belum berperilaku peduli lingkungan dalam kehidupan sehari-hari. Berdasarkan hasil studi pada tahun 2012 yaitu Indeks Perilaku Peduli Lingkungan (IPPL) masyarakat Indonesia dalam kisaran angka 0,57 dari angka mutlak satu (Kambuaya, 2013).

Masyarakat merupakan subjek kehidupan. Sebab akibat segala permasalahan berakar pada masyarakat. Kualitas kepedulian masyarakat terhadap lingkungan yang baik, maka akan baik pula lingkungan di sekitarnya.
Sebaliknya, kualitas kehidupan yang buruk tentu implikasinya pada lingkungan berakibat buruk juga (Setyowati, 2018).

Ketidakmampuan dan keserakahan manusia dalam menggunakan berbagai kekayaan alam merupakan faktor utama penyebab permasalahan lingkungan yang terjadi (Andalas, 2018:100). Hal tersebut terjadi karena kurannya kesadaran manusia terhadap pentingnya menjaga lingkungan hidup. Kesadaran itulah yang seharusnya dibentuk sebagai karakter peduli lingkungan.

Karakter merupakan hal dasar dalam diri manusia, yang membedakan manusia dengan makhluk yang lainnya. Pembentukan karakter peduli lingkungan haruslah dibentuk sejak dini melalui berbagai macam kegiatan 
yang dapat menguatkan rasa kepedulian terhadap lingkungan.

Kegiatan-kegiatan yang dapat menguatkan rasa kepedulian terhadap lingkungan dapat dilakukan dengan pembiasaan-pembiasaan hidup sehat dan peduli lingkungan. Terdapat dua karakter peduli lingkungan yang perlu ditanamkan pada anak, yakni karakter peduli lingkungan sosial dan lingkungan alam. Karakter peduli lingkungan sosial merupakan usaha dalam memberikan bantuan kepada orang yang membutuhkan. Adapun karakter peduli alam merupakan perilaku dalam menjaga lingkungan alam sekitar (Azzet dalam Harlistyarintica, et al, 2017).

Penyadaran kepedulian terhadap lingkungan yang paling utama adalah dengan pendidikan lingkungan agar terbentuk masyarakat yang melek lingkungan (Yuniawan, dkk., 2018). Pendidikan karakter peduli lingkungan menjadi indikator kepedulian dan kepekaan siswa terhadap lingkungan belajarnya, sehingga dapat mewujudkan lingkungan yang sehat, nyaman serta dapat meningkatkan prestasi dan kreativitas siswa (Purwanti , 2017). Lingkungan tentu sangat berpengaruh pada prestasi siswa. Maka dari itu perlu diciptakannya lingkungan belajar yang nyaman dan sehat.

Siswa belum mampu menerapkan dengan baik pengetahuan dan keterampilan tentang lingkungan yang dimiliki dalam bentuk sikap dan perilaku melek lingkungan (Hermawan \& Susilo, 2018). Hal tersebut dapat dilihat dari pengetahuan siswa yang berkaitan dengan teori tentang lingkungan yang tidak sesuai dengan sikap dan perilakunya di kehidupan. Perilaku melek lingkungan dapat dikembangkan dengan menyesuaikan materimateri, aspek perkembangan kognitif peserta didik maupun lingkungan sekitarnya (Purwanti, Elly., dan Wahyu Prihanta, 2016).

Pendidikan lingkungan hidup harus diseimbangkan antara teoritis dan praktik. Pendidikan lingkungan hidup sangat penting karena merupakan salah satu usaha untuk melestarikan lingkungan yang dilakukakan dari generasi ke generasi berikutnya (Agsari, dkk., 2018). Siswa merupakan generasi penerus bangsa yang harus mendapatkan pentingnya pendidikan karakter peduli lingkungan.

Pembentukan serta penguatan karakter peduli lingkungan dapat diterapkan sejak anak menempuh pendidikan sekolah dasar, karena secara ilmiah anak pada usia ini memiliki rasa ingin tahu yang kuat, senang bermain, bereksperimen, memiliki semangat dalam bersaing, memiliki keinginan untuk belajar, ketika yang mereka inginkan telah terpenuhi, belajar dengan cara yang mereka inginkan. Berdasarkan uraian diatas, dapat disimpulkan bahwa pentingnya membentuk dan menguatkan karakter peduli lingkungan kepada anak atau siswa sekolah dasar, tanpa terkecuali siswa di Madrasah Ibtidaiah Muhammadiyah (MIM) Kranggan, kesadaran mereka terhadap lingkungan sekolah, kelas dan belajarnya terbilang masih rendah.

Berdasarkan uraian tersebut, kelompok KKNDik MIM Kranggan FKIP UMS berperan dalam pembentukan dan penguatan karakter peduli lingkungan di lingkungan MIM Kranggan. Serangkaian program cinta lingkungan berkaitan dengan pembentukan dan penguatan karakter peduli lingkungan melalui pembiasaan-pembiasaan hidup sehat dan peduli terhadap lingkungan kami rencanakan dan laksanakan.

\section{Metode Pelaksanaan}

Kegiatan pengabdian ini ditujukan kepada semua siswa MIM Kranggan yang berlokasi di Dusun Logantung, Desa Kranggan, Kecamatan Polanharjo, Kabupaten Klaten pada tanggal 21 Februari 2020 - 3 Maret 2020. Pelaksanan kegiatan pengabdian ini menggunakan beberapa metode diantaranya yaitu:

1. Sosialisasi, diberikan kepada siswa mengenai Perilaku Hidup Bersih dan Sehat (PHBS). Kegiatan sosialisasi ini dilaksanakan dengan menggunakan metode ceramah, brainstorming, dan tanya jawab yang bertujuan supaya siswa menyadari pentingnya menjaga kebersihan dan kesehatan. Tambak (2014) menyatakan metode ceramah merupakan suatu kegiatan yang memberikan penjelasan materi kepada siswa melalui bahasa lisan.

2. Pemberian reward, berupa pengadaan lomba kebersihan antar kelas yang dilaksanakan setiap pekan.

3. Gerakan kebaikan, berupa gerakan membawa tumbler ke sekolah dan penyediaan galon air minum yang diletakkan di depan kelas.

4. Praktik langsung, berupa gerakan menanam pohon yang melibatkan peran aktif siswa, untuk kemudian tanaman diletakkan di depan kelas. 


\section{Hasil Pelaksanaan dan Pembahasan}

Program cinta lingkungan sebagai bentuk pengabdian yang dilakukan oleh KKNDik FKIP UMS MIM Kranggan merupakan upaya penguatan karakter peduli lingkungan. Program ini dilatar belakangi oleh kondisi siswa MIM Kranggan yang kurang peduli terhadap lingkungan sekolah. Liyun et al, (2019) adanya urgensi penanaman pendidikan karakter berupa menjaga lingkungan hidup sejak dini, melalui penanaman pola pikir siswa.

Program cinta lingkungan terdiri dari empat kegiatan yang terintegrasi yaitu, sosialisasi PHBS (Perilaku Hidup Bersih dan Sehat), lomba kebersihan, gerakan membawa tumbler, dan gerakan menanam pohon.

\section{Sosialisasi PHBS}

Sosialisasi adalah proses belajar, belajar tingkah laku, kebiasaan, pola-pola kultural, dan keterampilanketerampilan sosial (Ismail, 2019). Tujuan sosialisasi supaya siswa belajar mengenai perilaku hidup bersih dan sehat. Siswa diharapkan mampu menyadari akan pentingnya menjaga kebersihan dan kesehatan, sehingga siswa terlindungi dari berbagai penyakit dan dapat fokus dalam mengikuti pembelajaran. Peserta sosialisasi ini merupakan siswa kelas 1-6. Siswa diberi sosialisasi mengenai perilaku hidup bersih dan sehat, yaitu mencuci tangan dengan benar, membeli makanan yang sehat, menggunakan toilet yang bersih dan sehat, mengikuti kegiatan olahraga dan beraktivitas fisik, memberantas jentik nyamuk, menghindari asap rokok, menimbang berat badan dan mengukur tinggi badan, dan membuang sampah pada tempatnya. Penggunaan media membuat siswa antusias dalam mengikuti sosialisasi ini. Media yang digunakan dalam sosialisasi ini adalah PowerPoint (PPt) yang didesain dengan gambar dan video yang menarik.

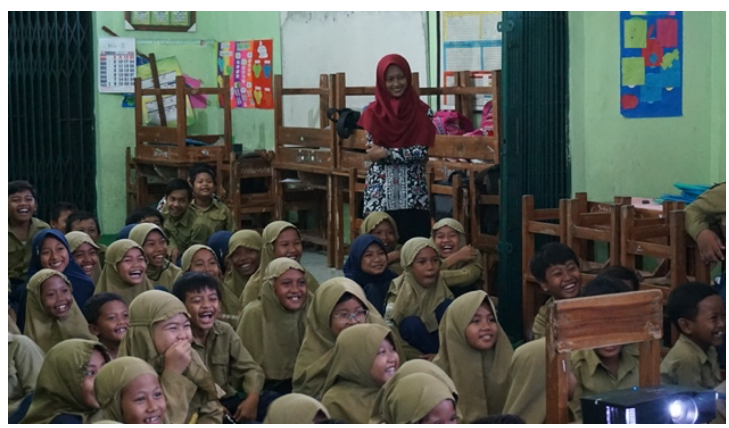

Gambar 1 Siswa Antusias dalam Mengikuti Sosialisasi PHBS

\section{Lomba Kebersihan}

Tujuan lomba ini adalah untuk menumbuhkan kesadaran siswa dalam menjaga kebersihan kelas. Penilaian lomba ini dilakukan sewaktu-waktu dan diumumkan satu pekan sekali secara rutin. Reward dapat memberikan efek pengulangan tingkah laku (Ernata, 2017). Lomba kebersihan ini memberikan dampak kepada siswa lebih termotivasi untuk selalu menjaga kebersihan kelas, seperti menjalankan tugas piket dan membuang sampah pada tempatnya.

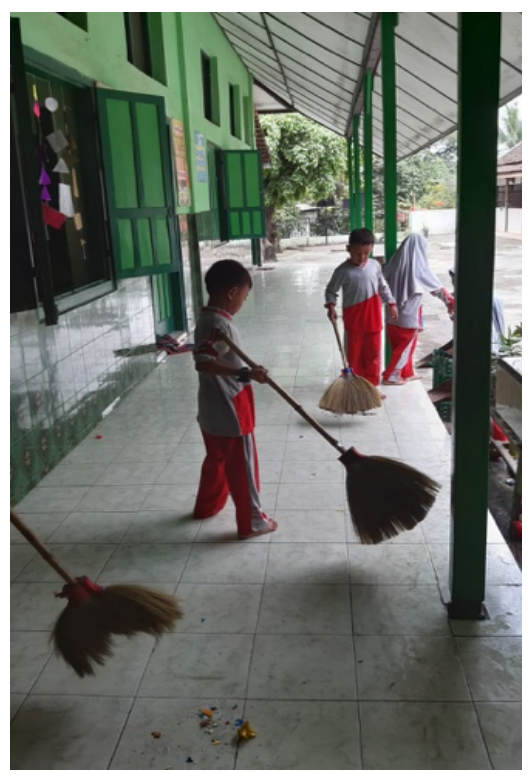

Gambar 2 Siswa Membersihkan Lingkungan Sekolah

\section{Gerakan Membawa Tumbler}

Berdasarkan data KLHK (Kementerian Lingkungan Hidup dan Kehutanan) total sampah plastik di Indonesia tahun 2019 mencapai 9,52 juta ton (Suara.com). Gerakan ini dilaksanakan agar siswa dapat berpartisipasi dalam pengurangan sampah plastik, selain itu juga untuk menjaga kesehatan tubuh. KKNDik FKIP UMS MIM Kranggan menyediakan dua galon air mineral untuk memfasilitasi berjalannya gerakan ini. Siswa senang dengan adanya fasilitas ini dan termotivasi untuk selalu membawa tumbler ke sekolah. 
e-ISSN 2716-0327

doi: 10.23917/bkkndik.v2i2.11846

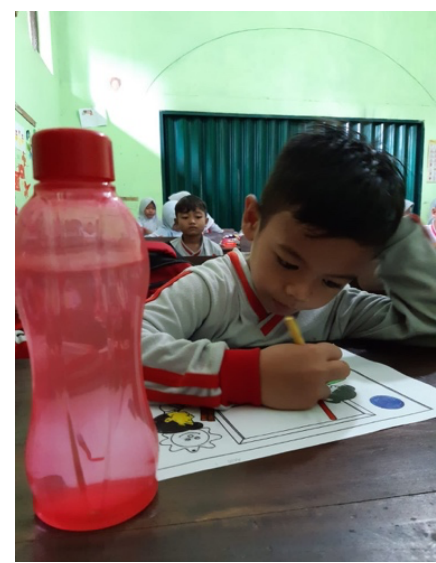

Gambar 3 Siswa Membawa Tumbler

\section{Gerakan Menanam Pohon}

Tujuan gerakan ini adalah untuk menumbuhkan kesadaran pentingnya penghijauan lingkungan sekolah. Siswa terlibat aktif dalam persiapan, penanaman, dan perawatan pohon. Persiapan penanaman pohon berupa pembuatan pot dari botol bekas.

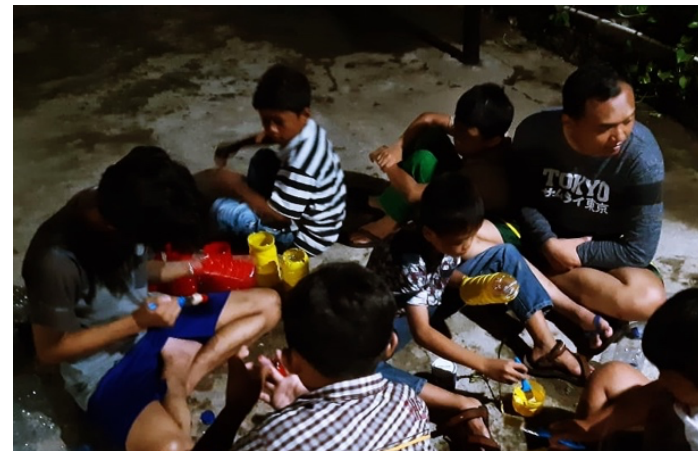

Gambar 4 Pembuatan Pot Meggunakan Botol Bekas

Siswa dilibatkan dalam penyiapan pohon yang akan ditanam, jenis pohon yang ditanam adalah bunga dan apotik hidup. Siswa antusias dalam penanaman pohon ini, dikarenakan siswa terlibat langsung. Keterlibatan langsung siswa dalam gerakan menanam pohon ini juga memberikan dampak pada siswa berupa rasa memiliki dan tanggung jawab terhadap pohon yang sudah ditanam.

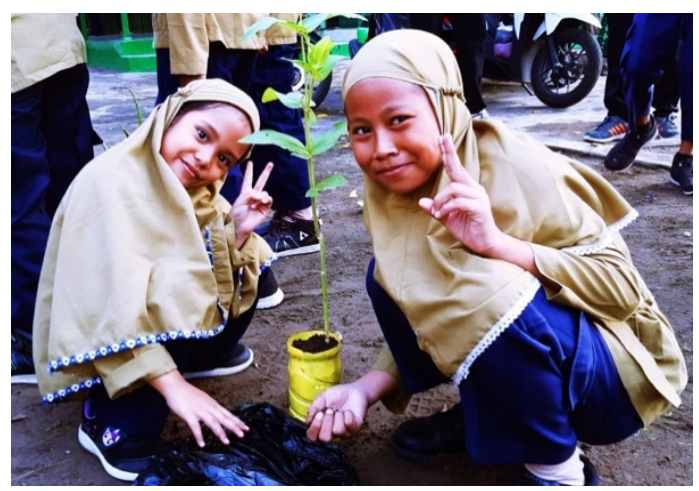

Gambar 5 Antusiasme Siswa dalam Penanaman Pohon

Pelaksanaan program cinta lingkungan ini memberikan hasil yang positif berupa antusiasme siswa dalam menjaga kebersihan lingkungan sekolah. Hal ini sejalan dengan tanggapan yang disampaikan oleh Kepala Sekolah MIM Kranggan, Ibu Musyarofah, S. Pd. I, bahwa program ini nantinya akan dilanjutkan dikarenakan memberikan efek pada perubahan kepedulian siswa dalam menjaga kebersihan kelas dan lingkungan sekolah yang sebelumnya masih kurang baik.

\section{Simpulan}

Program cinta lingkungan dilakukan untuk menguatkan karakter peduli lingkungan. Program cinta lingkungan terdiri dari empat kegiatan yang terintegrasi yaitu, sosialisasi PHBS (Perilaku Hidup Bersih dan Sehat), lomba kebersihan, gerakan membawa tumbler, dan gerakan menanam pohon. Program cinta lingkungan ini terlaksana dengan baik dan memberikan dampak positif berupa kepedulian siswa untuk menjaga lingkungan sekolah.

\section{Daftar Pustaka}

Agsari, Karenina Shashal., dkk, 2018. Development of EcoCulture to Improve Enviromental Literacy in Elementary School. 3rd National Seminar on Educational Innovation: Conference Series, 1(2): 217-222.

Andalas, Eggy Fajar. 2018. Literasi Ekologis: Tanggung Jawab Moral Ilmu Sastra dalam Pengelolaan Ekologi Manusia. Prosiding SENASBASA (Seminar Nasional Bahasa dan Sastra), Malang: 99-109.

Ernata, Y. (2017). Analisis Motivasi Belajar Peserta Didik Melalui Pemberian Reward dan Punishment di SDN Ngaringan 05 Kec. Gandusari Kab. Blitar. Jurnal Pemikiran dan Pengembangan SD, 5(2), 781-790.

Harlistyarintica, Y., Wahyuni, H., Widiyawanti, Yono, N., Sari, I. P., Cholimah, N. (2017). Penanaman 
Pendidikan Karakter Cinta Lingkungan Melalui Jari Kreasi Sampah Bocah Cilik di Kawasan Parangtritis. Jurnal Pendidikan Anak, 6(1), 20-30.

Hermawan, I.M.S., dan Herawati Susilo. 2018. Konsep Literasi Lingkungan dalam Perspektif Budaya Tri Hita Karana Masyarakat Bali: Sebuah Kajian Literatur. Prosiding Seminar Nasional Pendidikan Biologi, Malang: Juni 2018. Hal.696-703.

Ismail. (2019). Pentingya Sosialisasi Bagi Anak. UINSU: JISA (Jurnal Ilmiah Sosiologi Agama).

Kambuaya, B. (2013). Langkah Nyata Mengurangi Beban Pencemaran. Artikel Kementerian Lingkungan Hidup. $\quad$ http://www.menlh.go.id/surabaya-3rlangkah-nyata-mengurangi-beban-pencemaran diakses pada 11 Maret 2020.

Liyun, N., Khasanah, W. N., \& Tsuraya, N. A. (2019). Menanamkan Karakter Cinta Lingkungan pada Anak Melalui Program Green and Clean. Yogya: Prosiding Konferensi Pendidikan Nasional.

Purwanti, D. (2017). Pendidikan Karakter peduli Lingkungan dan Implementasinya. Jurnal Riset Pedagogik (DWIJACENDEKIA), 1(2), 14-20.
Purwanti, Elly., Wahyu Prihanta.2016. Penguatan Literasi Ekosistem Pada Siswa Klas X Dengan Specific Materi : Pembelajaran Ekosistem melalui Penelitian Ekofisiologi Hutan Mangrove. SENASPRO: Seminar Nasional dan Gelar Produk, Malang: 17-18 Oktober 2016. Hal. 155-163.

Setyowati. 2018. Problematika Lingkungan Hidup dalam Syair Lagu Populer Indonesia (Studi Ekologi Sastra). Jurnal Ilmiah FONEMA : Jurnal Edukasi Bahasa dan Sastra Indonesia, 1(1): 45-63.

Tambak, S. (2014). Metode Ceramah: Konsep dan Aplikasi dalam Pembelajaran Pendidikan Agama Islam. Jurnal Tarbiyah, 21(2), 375-401.

Yuniawan, Tommi., Ida Zulaeha., dan Meina Febriani. 2018. Peningkatan Literasi Ekoleksikon Konservasi Melalui Membaca Intensif Bagi Mahasiswa UNNES. Prosiding Seminar Nasional Kolaborasi Pengabdian Pada Masyarakat, Semarang: Desember 2018. Hal. $330-332$. 